7-1-2015

\title{
A Novel Approach to Lymphedema Management in Upper Extremity Amputations: A Case Report
}

\author{
Katie Polo \\ Midwestern University, polok@uindy.edu \\ Gali Gamble \\ Northwestern University
}

Follow this and additional works at: https://nsuworks.nova.edu/ijahsp

Part of the Occupational Therapy Commons

\section{Recommended Citation}

Polo K, Gamble G. A Novel Approach to Lymphedema Management in Upper Extremity Amputations: A Case Report. The Internet Journal of Allied Health Sciences and Practice. 2015 Jul 01;13(3), Article 3.

This Manuscript is brought to you for free and open access by the College of Health Care Sciences at NSUWorks. It has been accepted for inclusion in Internet Journal of Allied Health Sciences and Practice by an authorized editor of NSUWorks. For more information, please contact nsuworks@nova.edu. 


\title{
A Novel Approach to Lymphedema Management in Upper Extremity Amputations: A Case Report
}

\begin{abstract}
Many breast cancer survivors experience lymphedema complications from past medical management procedures such as axillary lymph node dissections and/or radiation therapy. These complications negatively affect the patient's health and overall quality of life. Occupational therapists (OT) certified in lymphedema management can contribute to positive patient outcomes as part of a comprehensive medical team. A case is presented of a 73-year-old female post voluntary trans-humeral amputation due to radiation induced brachial plexopathy. This patient's treatment was led by an OT certified in lymphedema management and included complete decongestive therapy and analysis of function with a focus on the development of a novel compression garment to support patient self-management.
\end{abstract}




\title{
iJAHSP
}

\section{The Internet Journal of Allied Health Sciences and Practice}

Dedicated to allied health professional practice and education

Vol. 13 No. 3 ISSN 1540-580X

\section{A Novel Approach to Lymphedema Management in Upper Extremity Amputations: A Case Report}

\author{
Katie Polo, MHS, OTR/L, CLT-LANA ${ }^{1}$ \\ Gail Gamble, MD2
}

1. Assistant Professor, Occupational Therapy Program, Midwestern University, Downers Grove, IL

2. Emeritus Associate Professor of Physical Medicine \& Rehabilitation, Feinberg School of Medicine, Northwestern University, Chicago, IL

\author{
United States
}

\begin{abstract}
Many breast cancer survivors experience lymphedema complications from past medical management procedures such as axillary lymph node dissections and/or radiation therapy. These complications negatively affect the patient's health and overall quality of life. Occupational therapists (OT) certified in lymphedema management can contribute to positive patient outcomes as part of a comprehensive medical team. A case is presented of a 73-year-old female post voluntary trans-humeral amputation due to radiation induced brachial plexopathy. This patient's treatment was led by an OT certified in lymphedema management and included complete decongestive therapy and analysis of function with a focus on the development of a novel compression garment to support patient self-management.
\end{abstract}

\section{INTRODUCTION}

The medical management of breast cancer has improved with the advancement of technology in radiology and surgical procedures. However, many breast cancer survivors who underwent medical management decades ago are now encountering side effects of their cancer treatments. These side effects can include brachial plexopathies, decreased sensation and/or neuropathies, lymphedema, and musculoskeletal disorders that can greatly impact quality of life (QOL). ${ }^{1}$ At the beginning of a brachial plexopathy, pain can occur in patients, and if the condition continues to worsen, both motor and sensory loss can occur months or even years later. ${ }^{2}$ Johansson et al tracked breast cancer survivors that received cobalt radiation decades ago, and $92 \%$ developed paralysis of the limb similar to our patient over time. ${ }^{3}$ Due to these longstanding complications of cancer treatment, some survivors are electing to undergo limb amputations. It is estimated that in 2020, 2.3 million people will be living with limb loss due to the effects of cancer. ${ }^{4}$

Lymphedema is also another late effect condition that is prevalent in breast cancer survivors. Cheifetz et al performed a systematic review of the literature on breast cancer-related lymphedema in intact limbs finding an incidence level ranging from $2 \%$ to $83 \%{ }^{5}$ This disparity in incidence was recognized by the International Society of Lymphology's 2009 consensus document with encouragement of performing ongoing epidemiologic studies on incidence and prevalence worldwide. ${ }^{6}$ Olsen et al found $22 \%$ of radiation-induced brachial plexopathy patients developed lymphedema of the affected intact upper extremity. ${ }^{7}$ Literature is dismal in representing incidence of lymphedema in residual amputated limbs.

Treatment of lymphedema in intact limbs primarily consists of complete decongestive therapy (CDT) that involves two phases, an intensive phase that is performed alongside a trained lymphedema occupational or physical therapist, and a maintenance phase that transitions the patient to self-management of lymphedema at home. The intensive phase has a standardized protocol focusing on meticulous skin and nail care, manual lymphatic drainage, compression bandaging, remedial exercises, and selfcare training. The maintenance phase embodies the provision of education and information on continuation of at-home exercises and self-maintenance of lymphedema as well as the prescription of a compression garment for adequate daily containment. ${ }^{8}$ $\mathrm{CDT}$ is the "gold standard" in care and has been found to be efficacious in numerous studies on intact lymphedematous limbs. ${ }^{9-13}$

(C) The Internet Journal of Allied Health Sciences and Practice, 2015 
Beyond the use of traditional stump shrinkers for post -operative swelling, there is a paucity of research pertaining to the containment of cancer-related lymphedema for patients with trans-humeral amputations. ${ }^{14,15}$

During patient care, it is imperative an OT implements the use of professional skills in the area of activity and analysis regardless of the client's condition. The Occupational Therapy Practice Framework states activity analysis is an important process occupational therapists use to understand the demands a specific activity places on a patient. ${ }^{16} \mathrm{An}$ OT certified in lymphedema therapy provided treatment and orchestrated implementation of activity and analysis within this case ultimately leading to overall success with development of a novel compression garment for ongoing containment.

The purpose of this case report is to describe the complete decongestive therapy of a 73-year old female post voluntary transhumeral amputation due to radiation induced brachial plexopathy and longstanding history of lymphedema. In addition, we highlight the contributions of the occupational therapist certified in lymphedema management as an integral part of our interdisciplinary team.

\section{CASE HISTORY}

The patient was a 73-year-old female with chief complaints of lymphedema and slowed incision healing of her left residual limb and trunk after a voluntary left short trans-humeral amputation. In 1970, she was diagnosed with left infiltrating ductal carcinoma breast cancer for which she underwent a radical mastectomy, total axillary lymph node dissection, and extensive cobalt radiation at the time for her medical treatment. Immediately following this surgery, she developed chronic, longstanding lymphedema. In 1990, she developed signs and symptoms of numbness and tingling consistent with a brachial plexopathy and by 1999 the patient's motor impairments progressed into a flail non-functional limb. This patient expressed decreased proprioception and sensation from the brachial plexopathy and heaviness from the lymphedematous limb which resulted in gait instability and loss of balance leading to several patient falls and resultant fractures. Eventually she voluntarily opted for a left upper extremity short trans-humeral amputation after the option was presented secondary to fear of future falls with fractures, and self-perceived overall poor quality of life. Unconnected to this, the patient also had a past medical history of right invasive ductal carcinoma in situ (DCIS) and underwent a modified radical breast mastectomy with sentinel node biopsy. No complications were reported by the patient on the right side. Previous therapy for her chronic lymphedema was performed in the 1990s and into 2003 consisting of compression bandaging, manual lymphatic drainage (MLD), passive range of motion, and compression garment distribution. At the time of her amputation surgery, her left limb lymphedema was controlled with the use of a flat knit compression sleeve and glove that required total assistance for donning.

Post operatively, the patient was referred to the director of amputee services at a large rehabilitation hospital from the surgeon for continued follow-up care. At her first post-op appointment, the patient was measured for a traditional limb shrinker from the amputee/orthotics department, but it was determined she did not qualify for this compression mechanism due to the large circumference of her residual limb. The patient also verbalized preference for wearing a breast prosthesis, which would interfere with a shrinker's suspension system. As an alternative at the time, the orthotics department placed her residual limb into a double layer of elastic tubular stockinette with silicone lining in efforts to decrease her limb volume. A month later the patient developed open weeping blisters at the surgical incision likely due to friction of the stockinette. The director of amputee services discontinued the use of the elastic tubular compression for wound healing, and at that time, referred the patient to our outpatient lymphedema rehabilitation clinic for left residual limb and truncal volume reduction, improvement of skin integrity, hygiene preservation, and a home program. This outpatient lymphedema rehabilitation clinic team consisted of a cancer physiatrist, an occupational therapist certified in lymphedema, an occupational therapy student, a durable medical equipment compression provider, and a rehabilitation engineer.

\section{Occupational Therapy Evaluation and Intervention}

The OT evaluation findings indicated the need for treatment of CDT for lymphedema reduction due to limb volume size, the need for a custom compression garment to fit the residual limb, the need for a proper compression garment with modifications for an end result of patient independence with donning, and ADL intervention to properly don the garment independently. The patient was seen in the clinic for occupational therapy lymphedema services two to three times per week for an initial duration of four weeks with sessions lasting 45 minutes focusing on CDT. CDT intervention during this active phase focused on meticulous skin care, manual lymphatic drainage (MLD), compression bandaging of the residual limb and affected trunk, remedial exercises, and self-care training. The first three weeks of therapy also focused on training the patient's husband for at-home application of skin hygiene and moisturization routine, MLD, and compression bandaging. Special attention was required during the compression bandaging process to contain the specific bulbous contour of the residual limb and concavities of the chest wall. Substantial differences in post-amputation dressing practices are present today due to the lack of consensus on best practices in present literature. ${ }^{17}$ Edema reduction was achieved with soft, two-way compression bandages (one eight centimeter bandage; one 10

(C) The Internet Journal of Allied Health Sciences and Practice, 2015 
centimeter bandage). A standardized application of bandaging was achieved with pictured instruction sheets given to the patient for home maintenance. After four weeks, the patient was measured for progress and treatments were continued for two times per week for another four weeks to focus on at-home self-maintenance, compression garment fitting, and training. There are many validated measurements for calculating limb volumes such as water displacement, use of tape measurements to calculate limb volume, bioimpedance analysis, and perometry. Due to the reduced length of the residual limb and the clinic's limited resources, perometry and bioimpedance were not options for volume measurement at the time of this patient's evaluation. Over the entire 2 month period of treatment, weekly circumference measurements and photos were taken to measure progress during the active treatment phase (See Tables $1 \&$ 2).

\section{Intervention Outcome}

Table 1. Weekly Circumferential Measurements expressed in centimeters (cm)

\begin{tabular}{|c|c|c|c|c|c|c|c|}
\hline & 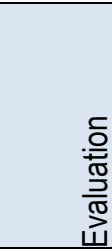 & 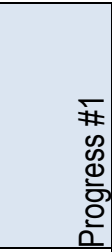 & 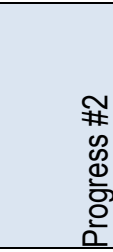 & 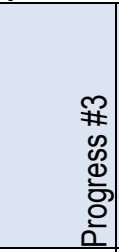 & 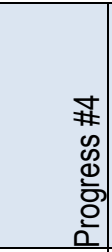 & 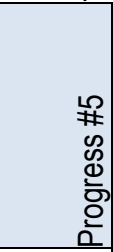 & 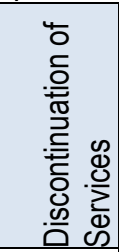 \\
\hline \multicolumn{8}{|l|}{$\begin{array}{l}\text { Residual Limb } \\
\text { Measurements }\end{array}$} \\
\hline $\begin{array}{l}\text { In alignment of mole at } \\
\text { distal end of limb }\end{array}$ & 27.8 & 26.7 & 25.4 & 25.2 & 23.5 & 23.4 & 22.6 \\
\hline $4 \mathrm{~cm}$ proximal to mole & 29.2 & 28.4 & 26.3 & 26.1 & 25.1 & 26.3 & 25.1 \\
\hline $\begin{array}{l}\text { Vertical circumference } \\
\text { around shoulder }\end{array}$ & 35.3 & 33.4 & 32.2 & 31.4 & 31.4 & 33.1 & 30.9 \\
\hline \multicolumn{8}{|l|}{ Trunk Measurements } \\
\hline At bilateral axillary crease & 77.3 & 78.9 & 76.5 & 78.5 & 77.1 & 77.7 & 77.2 \\
\hline $\begin{array}{l}6 \mathrm{~cm} \text { distal to } \mathrm{L} \text { axillary } \\
\text { crease }\end{array}$ & 77.2 & 77.0 & 74.8 & 75.5 & 75.2 & 76.1 & 75.3 \\
\hline $\begin{array}{l}12 \mathrm{~cm} \text { distal to } \mathrm{L} \text { axillary } \\
\text { crease }\end{array}$ & 75.9 & 77.2 & 74.5 & 74.9 & 74.6 & 78.1 & 76.6 \\
\hline $\begin{array}{l}16 \mathrm{~cm} \text { distal to } L \text { axillary } \\
\text { crease }\end{array}$ & 76.7 & 76.8 & 73.5 & 75.9 & 77.0 & 78.7 & 75.2 \\
\hline
\end{tabular}


Table 2: Weekly Progress Photos

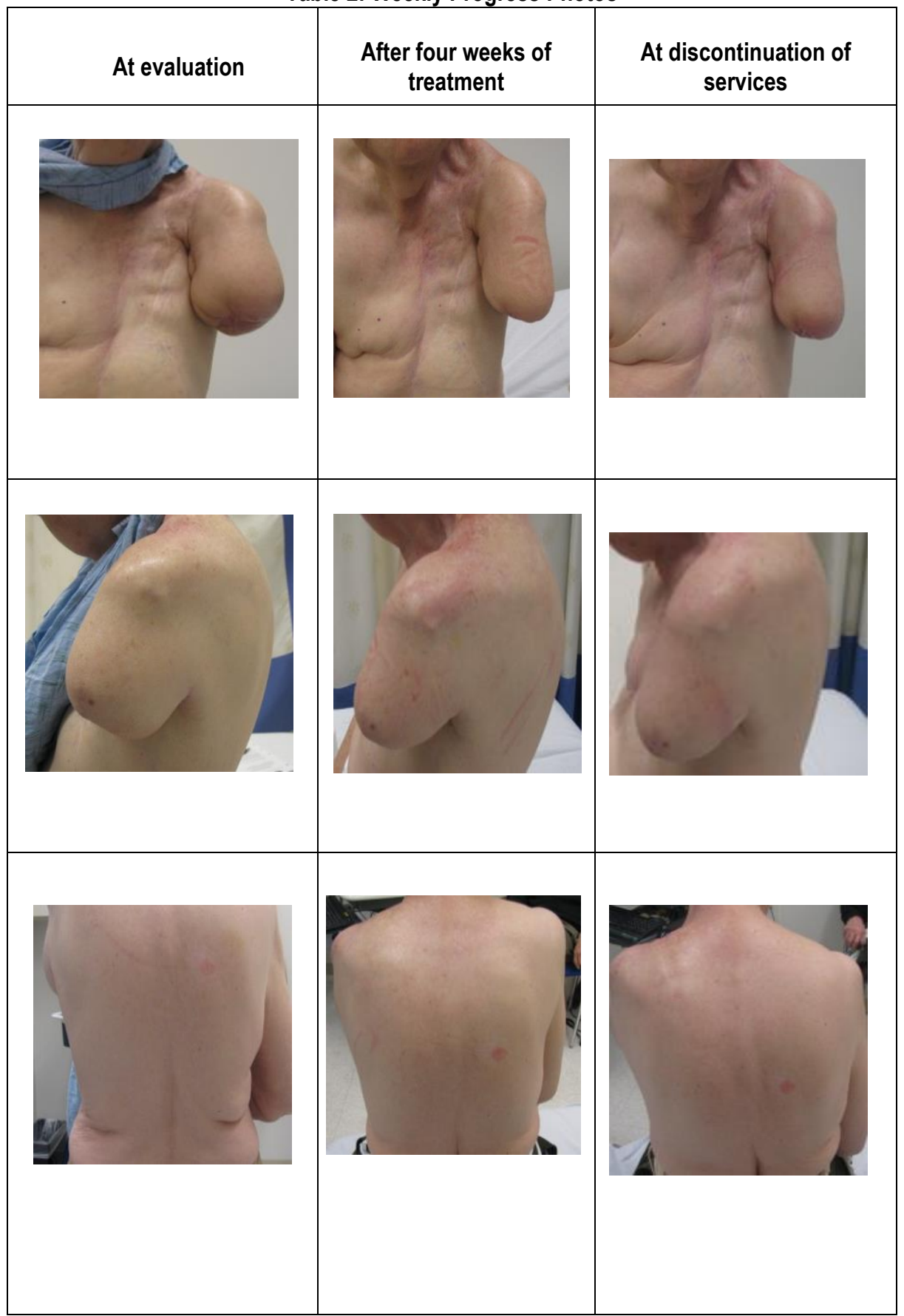

A compression garment consultation and a self-management home program were started on the fourth week of treatment. The garment selection was guided by the occupational therapist's client-centered approach in keeping the patient's priority goal for complete independence with compression sleeve placement and removal at the forefront of the care plan. Other considerations for this priority were the patients concern for breast prosthesis wear alongside the garment. The therapist also considered that ease with donning and removing the garment would improve overall compliance with patient's lymphedema self-management. The rehabilitation engineer was available for consultation at each appointment if deemed necessary by the outpatient occupational therapist. The team was critical to the success of garment development as previous post- operative attempts of compression offerings did not provide adequate containment nor achieved patient independence. The inter-professional team's 
response to continued patient centered feedback was vital for the ultimate success of this challenging compression garment development process. Multiple compression garments were considered as listed below:

1.) Custom compression vest with shoulder cap for increased trunk and residual limb containment: this option was ruled out secondary to patient's concern for inability to independently don and doff, as well as possible friction, discomfort, and risk of skin integrity on the chest wall;

2.) Custom fabricated flat knit compression garment: this option was ruled out due to expense of the garment and possible difficulty independently donning and doffing the garment.

3.) Ready-to-wear compression sleeve with shoulder cap and posterior anchor short sleeve component to contralateral arm: this was the compression option selected. Clinical reasoning for the final decision was due to the potential for increased compression to shoulder and posterior trunk regions, less expense than a custom compression garment, and patient predicted independence in donning and doffing garment.

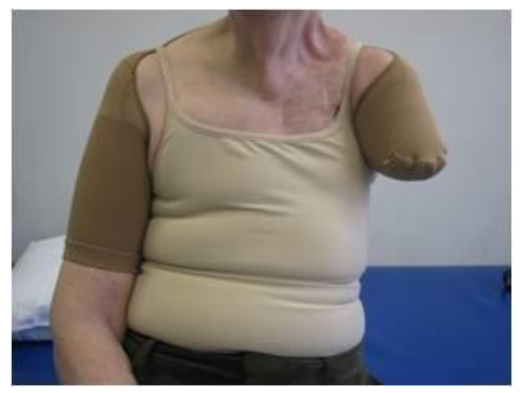

Figure 1: Final Compression Garment

The chosen garment was modified by the rehabilitation engineer after recommendations from the OT considering proper compression for containment of the residual limb and ability for the patient to be independent with use. The specific skills in activity and analysis guided the OT in predicting the patient's independence in donning and removing the recommended garment. Therefore, the changes in the traditional garment lead to a customized novel compression garment specifically geared toward this individual's needs (See Figure 1 for final compression garment). Garment distribution occurred at week six with functional care training for donning independently, and further garment modifications continued into week seven for proper fit. At week eight, the patient was able to don her new compression garment independently and arrived for a garment check one week later with good containment results noted. These results were classified as no increases of swelling more than $2 \mathrm{~cm}$ at each measurement point as indicated in the clinical practice guidelines for breast cancer rehabilitation. ${ }^{18}$

The patient had marked anecdotal and tape measurement reductions of the residual limb and trunk region during the active treatment phase. These clinically significant reductions from evaluation to after her active treatment phase (as indicated on Table I as Evaluation \& Progress \#3) in the residual limb are as follows: a decrease of 2.6 centimeters $(\mathrm{cm})$ at the distal part of the residual limb, a decrease of $3.1 \mathrm{~cm}$ four centimeters proximal to the distal measurement, and a decrease of $3.9 \mathrm{~cm}$ for the shoulder measurement. This reduction was maintained with daily independent use of her fabricated "custom" developed compression garment. After garment distribution, a one-week follow-up and successive appointments revealed continued decreases in circumferential tape measurement of the residual limb with reductions as follows from after her active treatment phase to discontinuation of services (as indicated on Table 1 as the difference between Progress \#3 \& Discontinuation of Services): a continued decrease of $2.6 \mathrm{~cm}$ at the distal part of the residual limb, an additional decrease of $1.0 \mathrm{~cm}$ four centimeters proximal to the distal measurement, and an additional decrease of $.5 \mathrm{~cm}$ for the shoulder measurement which indicated self-containment. The patient had no further skin integrity issues over the surgical incisions and also had no infection incidence after successful edema management. Trunk measurements fluctuated from evaluation to after her active treatment phase (as indicated on Table 1 as Evaluation \& Progress \#3) in the trunk are as follows: an increase at axillary crease of .2cm, a decrease $6 \mathrm{~cm}$ distal to the axillary crease of $1.7 \mathrm{~cm}$, a decrease $12 \mathrm{~cm}$ distal the axillary crease of $1 \mathrm{~cm}$, and a decrease $16 \mathrm{~cm}$ distal to the axillary crease of $.8 \mathrm{~cm}$. A six month follow-up appointment with the same lymphedema certified occupational therapist and cancer outpatient physiatrist revealed continued independence with the assigned program, excellent containment, and ongoing compliance with customized compression garment. 


\section{DISCUSSION}

While complete decongestive therapy is supported in the literature for patients with intact limbs, our case report demonstrates that this treatment paired with a novel compression garment was effective in decreasing lymphedema in the trans-humeral amputation patient.9-13 The OT treatment approach, including complete decongestive therapy and activity and analysis, reduced the patient's lymphedema, increased independence in donning and removing a novel compression garment, and increased engagement in ongoing self-management of lymphedema. Therefore, an OT certified in lymphedema therapy has an essential role to play in the management of the complex cancer-related amputee patient.

Limitations of this case report maybe the use of tape measurement rather than a more reliable form of lymphedema measurement. However, one literature sources states that it often suffices to take measurements at four reproducible and welldocumented landmarks consistently throughout therapy. ${ }^{8}$ Measurements in this case were taken starting at the patient's landmark, a mole on the distal end of the residual limb, to ensure reliable measurements throughout treatment. Truncal measurements fluctuated throughout treatment possibly because fluid from the residual limb was reduced into the trunk and shoulder girdle. The patient also had severe longstanding radiation fibrosis in the chest wall, thus reducing lymphatic transport. This fibrosis was not formally assessed or measured nor was it treated manually.

\section{CONCLUSION}

Further studies are needed to support efficacious treatment of chronic lymphedema patients living with trans-humeral amputations, and this case report serves to stimulate further investigations. The special skills of an OT certified in lymphedema therapy are needed on an interdisciplinary team working with breast cancer survivors. Novel approaches, similar to our program, should be further explored and reported to enhance the care of breast cancer survivors with lymphedema and secondary upper extremity amputations.

\section{REFERENCES}

1. Truong PT, Olivotto IA, Whelan TJ, Levine M, Steering Committee on Clinical Practice Guidelines for the Care and Treatment of Breast Cancer. Clinical practice guidelines for the care and treatment of breast cancer: Locoregional postmastectomy radiotherapy. CMAJ. 2004;170(8):1263-73. [PMID 15078851]

2. Johansson S. Radiation induced brachial plexopathies. Acta Oncologica. 2006;45:253-7.

3. Johansson S, Svensson H, Denekamp J. Timescale of evolution of late radiation injury after postoperative radiotherapy of breast cancer patients. Int J Radiation Oncology Biol Phys. 2000;48(3):745-50. [PMID 11020571]

4. Ziegler-Graham K, MacKenzie E.J, Ephraim PL, et al. Estimating the prevalence of limb loss in the United States: 2005 to 2050. Arch Phys Med Rehabil. 2008;89(3):422-9. [PMID 18295618]

5. Cheifetz $\mathrm{O}$, Haley L, Breast Cancer Action. Management of secondary lymphedema related to breast cancer. Can Fam Physician. 2010;56(12):1277-84. [PMID 21375063]

6. International Society of Lymphology. The diagnosis and treatment of peripheral lymphedema: 2013 Consensus document of the International Society of Lymphology. Lymphology. 2013;46(1):1-11. [PMID 23930436]

7. Olsen NK, Pfeiffer P, Mondrup K, Rose C. Radiation-induced brachial plexus neuropathy in breast cancer patients. Acta Oncol. 1990;29(7):885-90. [PMID 2261203]

8. Foldi M, Foldi E, Kubik S. Textbook of Lymphology: For Physicians and Lymphedema Therapists. San Francisco, CA: Urband \& Fischer; 2006.

9. Didem K, Ufuk YS, Serdar S, Zumre A. The comparison of two different physiotherapy methods in treatment of lymphedema after breast surgery. Breast Cancer Res Treat. 2005;93(1):49-54. [PMID 16184458]

10. Hamner JB, Fleming MD. Lymphedema therapy reduces the volume of edema and pain in patients with breast cancer. Ann Surg Oncol. 2007;14(6):1904-8. [PMID 17342565]

11. Pinell XA, Kirkpatrick SH, Hawkins $K$, Mondry TE, Johnstone PA. Manipulative therapy of secondary lymphedema in the presence of locoregional tumors. Cancer. 2008;112(4):950-4. [PMID 18085587]

12. Vignes $\mathrm{S}$, Porcher R, Champagne A, Dupuy A. Predictive factors of response to intensive decongestive physiotherapy in upper limb lymphedema after breast cancer treatment: A cohort study. Breast Cancer Res Treat. 2006;98(1):1-6. [PMID 16752081]

13. Yamamoto $T$, Todo $Y$, Kaneuchi M, Handa $Y$, Watanabe $K$, Yamamoto R. Study of edema reduction patterns during the treatment phase of complex decongestive physiotherapy for extremity lymphedema. Lymphology. 2008;41(2):80-6. [PMID 18720915]

14. Brady W. Post-operative management of lower extremity amputees using tubular elastic compression bandaging. Clinical Prosthetics and Orthotics. 1982;6:8-10. 
15. Field M, Zettl J. The design and testing of a gradient pressure sock for control of edema. Clinical Prosthetics and Orthotics. 1987;11:20-32.

16. American Occupational Therapy Association. Occupational therapy practice framework: Domain and process ( $3^{\text {rd }}$ ed.). American Journal of Occupational Therapy. 2014;68:S1-48.

17. Duwayri Y, Vallabhaneni R, Kirby J, Mueller MJ, Volshteyn O, Geraghty PJ, Sicard GA, Curci JA. Early Protection and Compression of Residual Limbs May Improve and Accelerate Prosthetic Fit: A Preliminary Study. Annals of Vascular Surgery. 2012;26(2):242-9. [PMID 22050879]

18. Harris SR, Schmitz K, Campbell KL, McNeely ML. Clinical Practice Guidelines for Breast Cancer Rehabilitation. Cancer. 2012;118(8 Suppl):2312-24. [PMID 22488705] 